\title{
Original
}

\section{Molecular Sensing for Organic Guests by Cyclodextrins Modified with Anthranilate Moieties}

\author{
by \\ Fumio $\mathrm{HAmada}^{\dagger}$, Kyoko Ishikawa ${ }^{\dagger}$, Itsu $\operatorname{Tamura}^{\dagger}$, Kouichi MuraI ${ }^{\dagger}$, \\ Youichi Akagami ${ }^{\dagger \dagger}$ and Akihiko Ueno ${ }^{\dagger \dagger}$
}

\begin{abstract}
Cyclodextrins modified with sodium anthranilate $(1-\beta, 2-\beta$ and 1- $\alpha$ ) have been synthesized as a sensing molecular for organic guests including terpenoids and bile acids. These host compounds show a pure monomer fluorescence with increasing or decreasing by accommodation of guest species. The extent of fluorescence variation with a guest is used to display the sensing factor $\left(\Delta \mathrm{I} / \mathrm{I}^{0}\right)$ of these host molecules. Among thc host molecules, 1- $\beta$ which is modified with bis sodium 2-aminobenzoate at primary hydroxy side of the $\beta$-cyclodextrin, shows the highest sensing factor. The molecularrecognition behavior of 1 - $\beta$ shows two ways depending on a guest molecule size; one way is both of the modification residues are coming into the cavity when larger guest such as bile acids were used and another way is the appended ones moving out of the cavity when a relative small guest such as terpenoids were used. Compounds $2-\beta$, which is capped with amino benzene carboxylate on the primary hydroxy side of $\beta$-cyclodextrin and $\alpha$-cyclodextrin modified with an anthranilate $(\mathbf{1}-\alpha)$ hardly display sensing ability for bile acids, it is probably caused by the low mobility of the appended residue of $2-\beta$ and a smaller cavity size of $1-\alpha$.
\end{abstract}

Key Word: Cyclodextrin, Fluorescent Sensor, Sodium 2-aminobenzoate

\section{Introduction}

Cyclodextrin, torus-shaped cyclic oligomers of D-glucopyranose and named $\alpha-, \beta$-, and $\gamma$ - for hexa, hepta and octamers, respectively, can make a host-guest complexation with a variety of organic compounds in their cavity in aqueous solution. ${ }^{1)}$ When we study a host-guest complexation bchavior of native cyclodextrins by spectroscopic method such as fluorescence, spectral shifts, fluorescence quenching, fluorescence polarization and induced circular dichroism (ICD), spectroscopically active guests should be used, because cyclodextrins themselves are spectroscopically inert. The modification of cyclodextrins with chromophores has aroused considerable interest because the

\footnotetext{
Received August 31, 1995

$\dagger$ Department of Materials Engineering and Applied Chemistry, Mining College, Akita University, Tegata, Akita 010, Japan

$\dagger \dagger$ Akita Prefectural Industrical Center, 4-11 Sanuki, Araya, Akita 010, Japan

$\dagger \dagger \dagger$ Department of Bioengineering, Faculty of Bioscience and Biotechnology, Tokyo Institute of Technology, Nagatsuta 227
} 
modification can be cxpected to improve or alter their host-guest complexation properties. ${ }^{2)}$ For last decade, we reported several types of host-guest complexation patterns of modified cyclodextrins bearing chromophores such as naphthalene, anthracene, pyrene, azobenzene, ferrocene, spiropyran and fluorescein moieties ${ }^{3)}$, whose the appended residue acts as a probe of the host-guest binding behavior together with a spacer to regulate a cavity size of the cyclodextrin or a hydrophobic cap to elevate the host-guest binding ability of the cyclodextrin. These molecules can be used to detect organic guest molecules, because they exhibit high selective and sensitive recognition ability of guest molecules. Recently, we reported a fluorescent host-guest sensing system using modified $\beta$ - and $\gamma$ cyclodextrins bearing an anthranilate moiety (3- $\beta$ and $1-\gamma$, respectively) and modified $\gamma$-cyclodextrin bearing two anthranilate moieties $(2-\gamma)$. $^{4}$ These cyclodextrin derivatives show unique complexation behaviors because of the smaller size of the anthranilate moiety in comparison with those of the appended moieties such as anthracene or napthalene moieties reported previously.

For further extension of the work, we prepared another type of anthranilate modified cyclodextrins, which are bis-sodium anthranilate modified $\beta$-cyclodextrin and amino benzene carboxylate capped $\beta$-cyclodextrin (1- $\beta$ and 2- $\beta$, respectively) together with sodium anthranilate modified $\alpha$-cyclodextrin (1- $\alpha$ ). Compound 1- $\beta$ shows higher sensitivity for bile acids than terpenoids. It is the first example showing that $\beta$-cyclodextrin derivative exhibits high sensitivity for larger guest such as bile acids than a small guest such as terpenoids. In this report, we would like to show the sensing abilities of the anthranilate modified cyclodextrins (1- $\beta, 2-\beta$ and 1- $\alpha$ ) together with the abilities of $\mathbf{3}-\beta, \mathbf{1}-\boldsymbol{\gamma}$ and $\mathbf{2}-\gamma$.

\section{Experimental}

Materials Prepation of bis-sodium anthranilate modified $\beta$-cyclodextrin $(1-\beta)$ and amino benzene carboxylate capped $\beta$-cyclodextrin (2- $\beta$ )

A mixture of (trans-azobenzene-4,4'-disulfonyl)- $\beta$-cyclodextrin ${ }^{5)}(1.07 \mathrm{~g}, 0.74 \mathrm{mM}$ ) and sodium anthranilate $(0.32 \mathrm{~g}, 2.01 \mathrm{mM})$ in DMF $(40 \mathrm{~mL})$ was heated at $80^{\circ} \mathrm{C}$ for $30 \mathrm{~h}$ under a nitrogen atmosphere. After cooling, the reaction mixture was poured into $300 \mathrm{~mL}$ of acetone. The resulting precipitates were collected by filtration and dried. The crude product was washed with ethanol to remove excess of sodium anthranilate and recrystallized from water to give $120 \mathrm{mg}$ of pure 1- $\beta$. $\mathrm{R}_{\mathrm{f}} 0.55$ (1-butanol : ethanol : water 5:4:3 by volume). ${ }^{1} \mathrm{H}-\mathrm{NMR}$ (DMSO- $\mathrm{d}_{6}$ ) 3.0-3.8 (42H, m, $\mathrm{C}_{2}-\mathrm{C}_{6} \mathrm{H}$ of cyclodextrin), 4.3-5.0 (12H, m, $\mathrm{O}_{6} \mathrm{H}, \mathrm{C}_{1} \mathrm{H}$ of cyclodextrin), 5.5-6.3 (14H, m, $\left.\mathrm{O}_{2} \mathrm{H}, \mathrm{O}_{3} \mathrm{H}\right), 6.5-6.8(5 \mathrm{H}$, $\mathrm{m},-\mathrm{NH}$ and aromatic- $\mathrm{H}), 7.25(1 \mathrm{H}, \mathrm{t}, \mathrm{J}=7.9 \mathrm{~Hz}$, aromatic-H), 7.65-8.25 (4H, m, aromatic-H). Found : C, $45.24 ; \mathrm{H}, 5.72 ; \mathrm{N}, 1.34 \%$. Calcd. for $\mathrm{C}_{56} \mathrm{H}_{78} \mathrm{O}_{37} \mathrm{~N}_{2} \mathrm{Na}_{2} \bullet 4 \mathrm{H}_{2} \mathrm{O}: \mathrm{C}, 5.16 ; \mathrm{H}, 5.82 ; \mathrm{N}, 1.88 \%$. $\operatorname{MS}(\mathrm{FAB}): 1373\left([\mathrm{M}-2 \mathrm{Na}+2 \mathrm{H}]^{+}\right)$. The mother liquid of $1-\beta$ was concentrated in vacuo and the residue was chromatographed on Sephadex G-15 $(3 \times 90 \mathrm{~cm})$ to afford $33 \mathrm{mg}$ of 2 - $\beta$ as pure compound. $\mathrm{R}_{\mathrm{f}} 0.49$ (1-butanol : ethanol : water 5:4:3 by volume). ${ }^{1} \mathrm{H}-\mathrm{NMR}$ (DMSO-d $\mathrm{d}_{6}$ ) 3.3-3.9 (42H, $\mathrm{m}, \mathrm{C}_{2}-\mathrm{C}_{6} \mathrm{H}$ of cyclodextrin), 4.2-5.0 (12H, m, $\mathrm{O}_{6} \mathrm{H}, \mathrm{C}_{1} \mathrm{H}$ of cyclodextrin), $5.7\left(14 \mathrm{H}\right.$, br.s, $\left.\mathrm{O}_{2} \mathrm{H}, \mathrm{O}_{3} \mathrm{H}\right)$, $6.53(1 \mathrm{H}, \mathrm{t}, \mathrm{J}=7.9 \mathrm{~Hz}$, aromatic- $\mathrm{H}), 6.60(1 \mathrm{H}, \mathrm{s}, \mathrm{NH}), 6.73(1 \mathrm{H}, \mathrm{d}, \mathrm{J}=7.9 \mathrm{~Hz}$, aromatic- $\mathrm{H}), 7.24$ $(1 \mathrm{H}, \mathrm{t}, \mathrm{J}=7.9 \mathrm{~Hz}$, aromatic-H), $7.72(1 \mathrm{H}, \mathrm{d}, \mathrm{J}=7.9 \mathrm{~Hz}$, aromatic- $\mathrm{H})$. Found : $\mathrm{C}, 45.17 ; \mathrm{H}, 6.10$; N, 1.13\%. Calcd. for $\mathrm{C}_{49} \mathrm{H}_{73} \mathrm{O}_{35} \mathrm{~N} \cdot 3 \mathrm{H}_{2} \mathrm{O}: \mathrm{C}, 45.16 ; \mathrm{H}, 5.82 ; \mathrm{N}, 1.13 \%$. MS (FAB) : $1236\left([\mathrm{M}+\mathrm{H}]^{+}\right)$. Preparation of mono-sodium anthranilate modified $\alpha$-cyclodextrin $(1-\alpha)$.

A-6-O-tosy- $\alpha$-cyclodextrin $1.16 \mathrm{~g}(1.03 \mathrm{mM})$ was added to a solution of $0.20 \mathrm{~g}(1.24 \mathrm{mM})$ of 
sodium anthranilate in $20 \mathrm{ml}$ of DMF. The reaction mixture was heated at $80^{\circ} \mathrm{C}$ for $23 \mathrm{~h}$ under a nitrogen atmosphere. After cooling, the reaction mixture was poured into $300 \mathrm{~mL}$ of acetone. The resultant precipitates were filtered and dried. The crude product was purified with a Sephadex G-15 column $(3 \times 90 \mathrm{~cm})$ to afford $0.42 \mathrm{~g}\left(36.9 \%\right.$ yield) of $1-\alpha . \mathrm{R}_{\mathrm{f}} 0.48$ (1-butanol : ethanol : water 5:4:3 by volume). ${ }^{1} \mathrm{H}-\mathrm{NMR}$ (DMSO- $\left.\mathrm{d}_{6}\right) 3.2-4.1\left(36 \mathrm{H}, \mathrm{m}, \mathrm{C}_{2}-\mathrm{C}_{6} \mathrm{H}\right.$ of cyclodextrin), 4.2-5.2 (11H, m, $\mathrm{O}_{6} \mathrm{H}$, $\mathrm{C}_{1} \mathrm{H}$ of cyclodextrin), 5.7-5.9 $\left(12 \mathrm{H}, \mathrm{m}, \mathrm{O}_{2} \mathrm{H}, \mathrm{O}_{3} \mathrm{H}\right), 6.8(1 \mathrm{H}, \mathrm{t}, \mathrm{J}=7.9 \mathrm{~Hz}$, aromatic- $\mathrm{H}), 6.9(1 \mathrm{H}, \mathrm{s}$, -NH), $7.0(1 \mathrm{H}, \mathrm{t}, \mathrm{J}=7.9 \mathrm{~Hz}$, aromatic-H), $7.5(1 \mathrm{H}, \mathrm{t}, \mathrm{J}=7.9 \mathrm{~Hz}$, aromatic- $\mathrm{H}, 8.0(1 \mathrm{H}, \mathrm{d}, \mathrm{J}=7.9$ $\mathrm{Hz}$, aromatic-H). Found : C, 45.52; H, $6.12 ; \mathrm{N}, 1.32 \%$. Calcd. for $\mathrm{C}_{43} \mathrm{H}_{64} \mathrm{O}_{31} \mathrm{NNa} \cdot \mathrm{H}_{2} \mathrm{O}: \mathrm{C}, 45.62 ; \mathrm{H}$, $5.87 ; \mathrm{N}, 1.24 \%$. MS (FAB) : $1092\left([\mathrm{M}-\mathrm{Na}+\mathrm{H}]^{+}\right)$.

\section{Measurements}

Ultraviolet, fluorescence and circular dichroism spectra were measured at $25^{\circ} \mathrm{C}$ with a Hitachi U-2000 spectrophotometer, a Hitachi F-3010 fluorescence spectrophotometer and JASCO J-700 spectropolarimeter, respectively. For the fluorescence measurements, the excitation wavelength of the fluorescence spectra was $330 \mathrm{~nm}$ and excitation and emission slits were $5 \mathrm{~nm}$. Ethylene glycol aqueous solution (10vol.-\%) was used as solvent for $1-\beta$ and $2-\beta$ for the spectroscopic measurements because the solubility of them in pure water is poor. Five microliteres of guest species $(0.5$, 0.05 and $0.005 \mathrm{M}$ ) in dimethy sulfoxide (DMSO) or methanol were injected into $10 \%$ ethylene glycol aqueous solution of $1-\beta$ and $2-\beta(2.5 \mathrm{~mL})$, and an aqueous solution of $1-\alpha(2.5 \mathrm{~mL})$ to make a sample solution with a host concentration of $1 \times 10^{-6} \mathrm{M}$ and guest concentration of $0.01,0.1$ and 1.0 $\mathrm{mM}$, respectively.

\section{Results and Discussion}

Fig. 1 shows the synthetic route for $1-\beta$ and $2-\beta$ from trans-azobenzene-capped $\beta$-cyclodextrin ${ }^{5)}$ and sodium anthranilate. Because trans-azobenzene-capped $\beta$-cyclodextrin was selectively
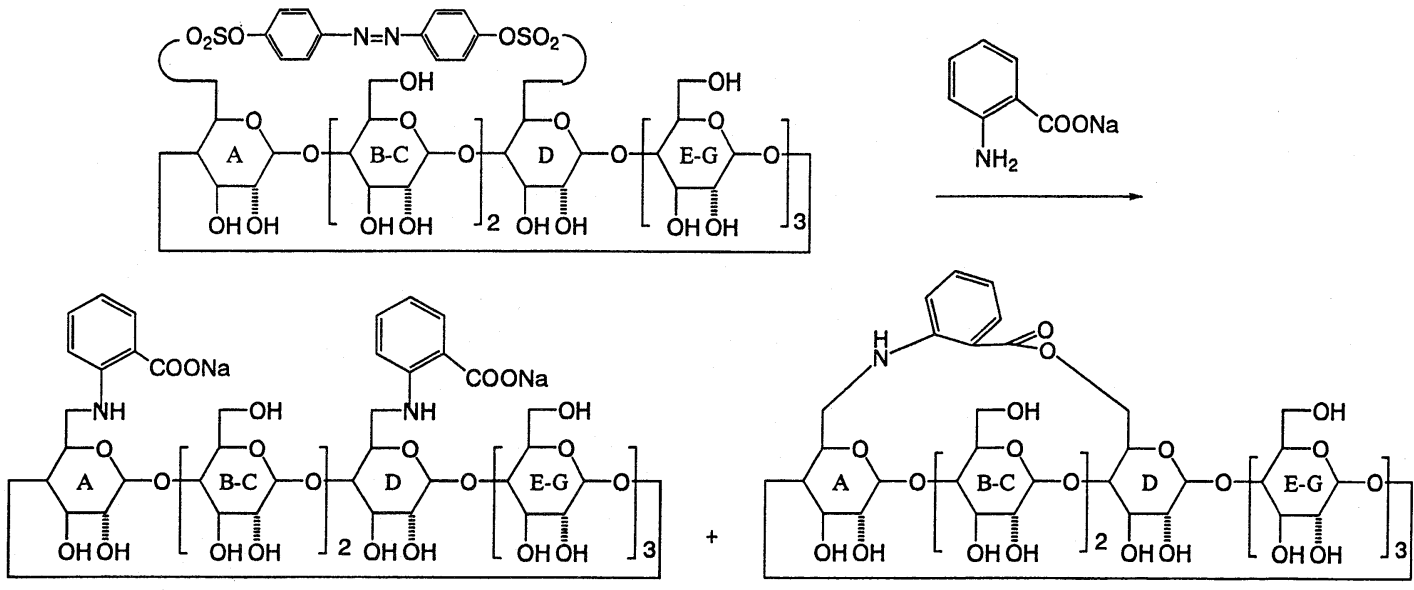

1- $\beta$

$2-\beta$

Figure 1. Preparation of $1-\beta$ and 2- $\beta$ from azobenzene capped $\beta$-cyclodextrin. 


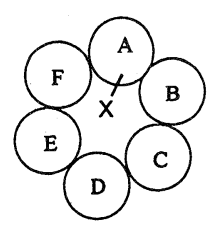

$1-\alpha$

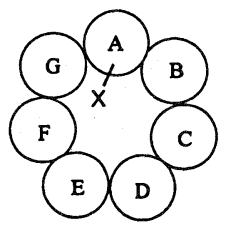

3- $\beta$<smiles>CC(C)=CCC/C(C)=C\CO</smiles>

nerol(1)

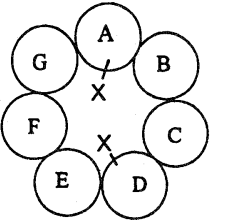

1- $\beta$

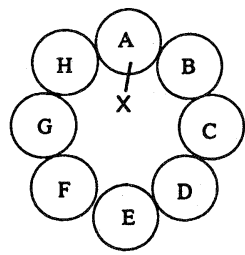

$1-\gamma$

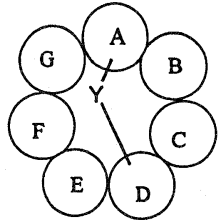

$2-\beta$

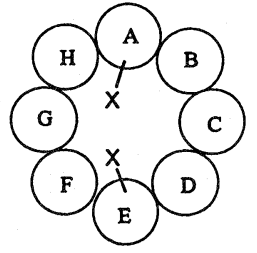

$2-\gamma$
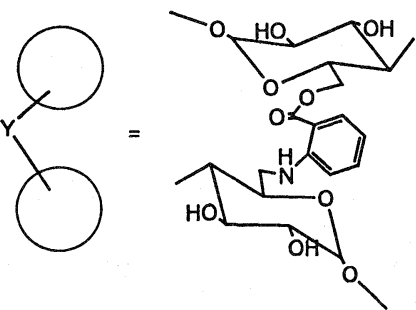

Chart 1<smiles>OC1CCCCC1</smiles><smiles>O=C1CCCCC1</smiles><smiles>CC(C)[C@H]1CC[C@@H](C)C[C@H]1O</smiles><smiles>OC1CCCCCCC1</smiles>

cyclooctanol(5)

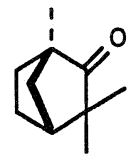

(+)-fenchone(6)<smiles>CC1(C)C(=O)[C@H]2C=C[C@@H]1C2</smiles>

(-)-fenchone(7)<smiles>CC1(C)C2CCC1C(O)C2</smiles>

(-)-borneol(8) 1-adamantanecarboxylic acid(9)

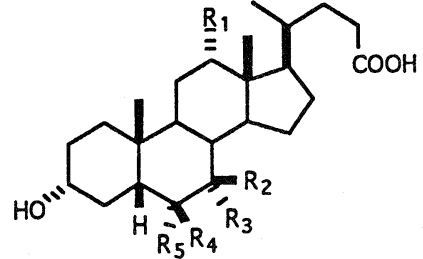<smiles>C[C@]12CCC3C4CCC[C@]35C[C@H](O)CC[C@]5(C)C1[C@H]4CCC2=O</smiles>

lithocholic acid(10): $R, R^{2}, R^{3}, R^{4}, R^{5}=H$ deoxycholic acid(11): $\mathrm{R}^{1}=\mathrm{OH}, \mathrm{R}^{2}, \mathrm{R}^{3}, \mathrm{R}^{4}, \mathrm{R}^{5}=\mathrm{H}$ chenodeoxycholic acid(12): $R^{1}, R^{2}, R^{4}, R^{5}=H, R^{3}=O H$ ursodeoxycholic acid(13): $\mathrm{R}^{1}, \mathrm{R}^{3}, \mathrm{R}^{4}, \mathrm{R}^{5}=\mathrm{H}, \mathrm{R}^{2}=\mathrm{OH}$ hyodeoxycholic acid(14): $\mathrm{R}^{1}, \mathrm{R}^{2}, \mathrm{R}^{3}, \mathrm{R}^{4}=\mathrm{H}, \mathrm{R}^{5}=\mathrm{OH}$ cholic acid(15): $\mathrm{R}^{1}, \mathrm{R}^{3}=\mathrm{OH}, \mathrm{R}^{2}, \mathrm{R}^{4}, \mathrm{R}^{5}=\mathrm{H}$

dehydroepiandrosterone(16)

Chart 2 

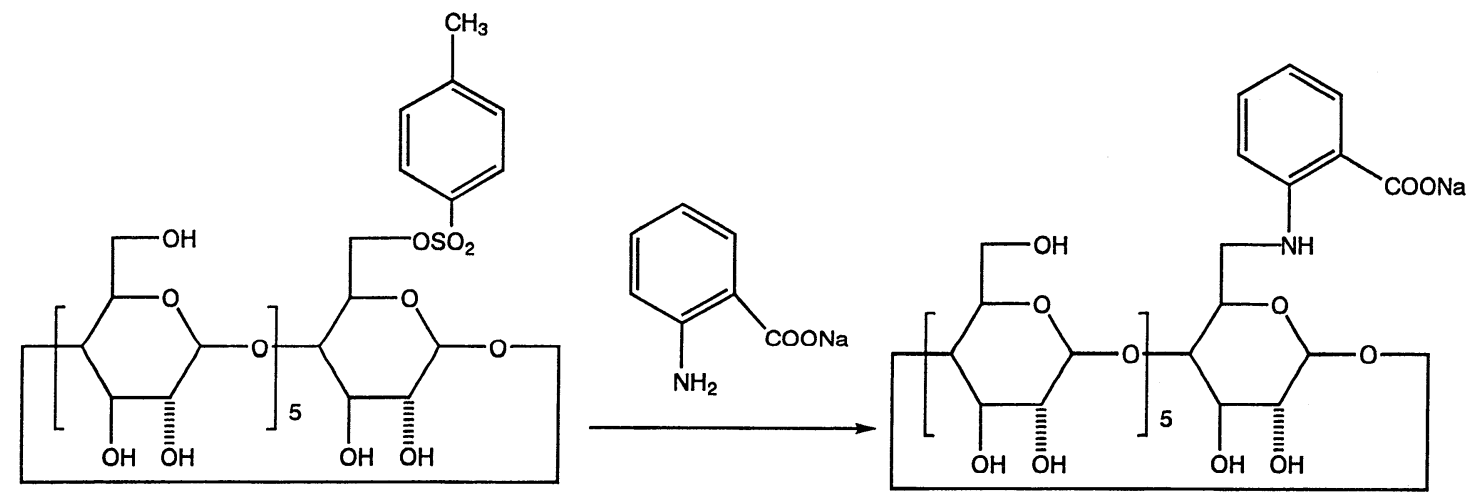

1- $\alpha$

Figure 2. Preparation of 1- $\alpha$.

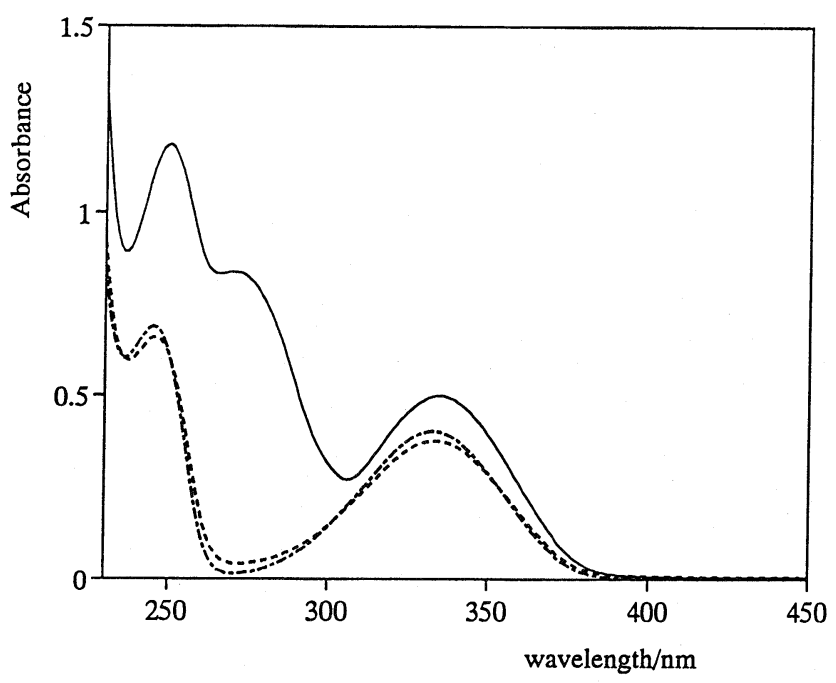

Figure 3. Absorption spectra of 1- $\beta$ (- $(-\beta$ (---------) in 10 vol.- $\%$ ethylene glycol aqueous solution $\left(10^{-4} \mathrm{M}\right)$ and $1-\alpha(---------)$ in aqueous solution $\left(10^{-4} \mathrm{M}\right)$.

sulfonated at primary hydroxyl groups of A-6-hydroxy and D-6-hydroxy in $\beta$-cyclodextrin, the appended moieties are introduced to the cyclodextrin regioselectively. Here, A and D mean that a glucose unit of the cyclodextrin as shown in Chart 1. Compound 2- $\beta$ was isolated as minor product. When we used trans-azobenzene-capped $\gamma$-cyclodextrin as starting material, a capped type compound like 2 - $\beta$ was not isolated, because $\gamma$-cyclodextrin cavity is too large to be linked by the aminobenzene carboxylate. Compound 1- $\alpha$ was synthesized from A-6-O-tosyl $\alpha$-cyclodextrin and sodium anthranilate as shown in Fig. 2. The absorption spectra of $1-\beta, 2-\beta$ in a 10 vol.- $\%$ ethylene glycol aqueous solution and 1- $\alpha$ in pure water are shown in Fig. 3. The pattern of the spectrum of 1- $\beta$, which has three peaks at around 250,270 and $340 \mathrm{~nm}$. On the other hand, the spectra of 2- 
$\beta$ and 1- $\alpha$ have not a peak at $270 \mathrm{~nm}$. It suggests that each the appended moiety of $1-\beta$ is in the different environment, that is, one is in the cavity and another is outside or around on the rim of the cyclodcxtrin cavity, because the optimized molecular mechanics calculations (MM2, Chem 3D plus) suggests that the cavity space is not so large to include both of the appended moieties. On the other hand, bis-sodium anthranilate modified $\gamma$-cyclodextrin (2- $\gamma$ ) can make intramolecular complex, in which both of the appended moieties are included in the cavity because of large cavity size of $\gamma$-cyclodextrin. ${ }^{4)}$ Fig. 4 shows the ICD spectra of $1-\beta$ alone or with a guest. When ursodeoxycholic acid was used as a guest, the $[\Theta]$ value of the negative band at around $260 \mathrm{~nm}$ increases with small extent. The positive band at around $320 \mathrm{~nm}$ increases with a large extent. On the other hand, the ICD spectra with (-)-menthol shows the decrease of the negative band at around $260 \mathrm{~nm}$ and a new negative band at around $350 \mathrm{~nm}$ appears with large intensity. This variational differencc of the ICD spectra suggest that a movement of the appended moieties are different when 1$\beta$ make a host-guest complexation with (-)-menthol and ursodeoxycholic acid. The fluorescence spectra of 1- $\beta$ alone or with ursodeoxycholic acid are shown in Fig. 5. The spectra of $1-\beta$ alone exhibits a peak at $424 \mathrm{~nm}$ whose intensity increases with a guest concentration increase. However, the intensity of the spectrum at $424 \mathrm{~nm}$ decreases whon terpenoids were used as a guest. It is reported that the guest-induced fluorescence enhancement means that the sodium anthranilate moiety moving into the cyclodextrin cavity deeply and the decrease means that the sodium anthranilate moiety moving out of the cavity. ${ }^{4}$ ) The results obtained from the ICD and fluorescence spectra of 1$\beta$ suggest that the movement of sodium anthranilate moieties undergo two ways associated with

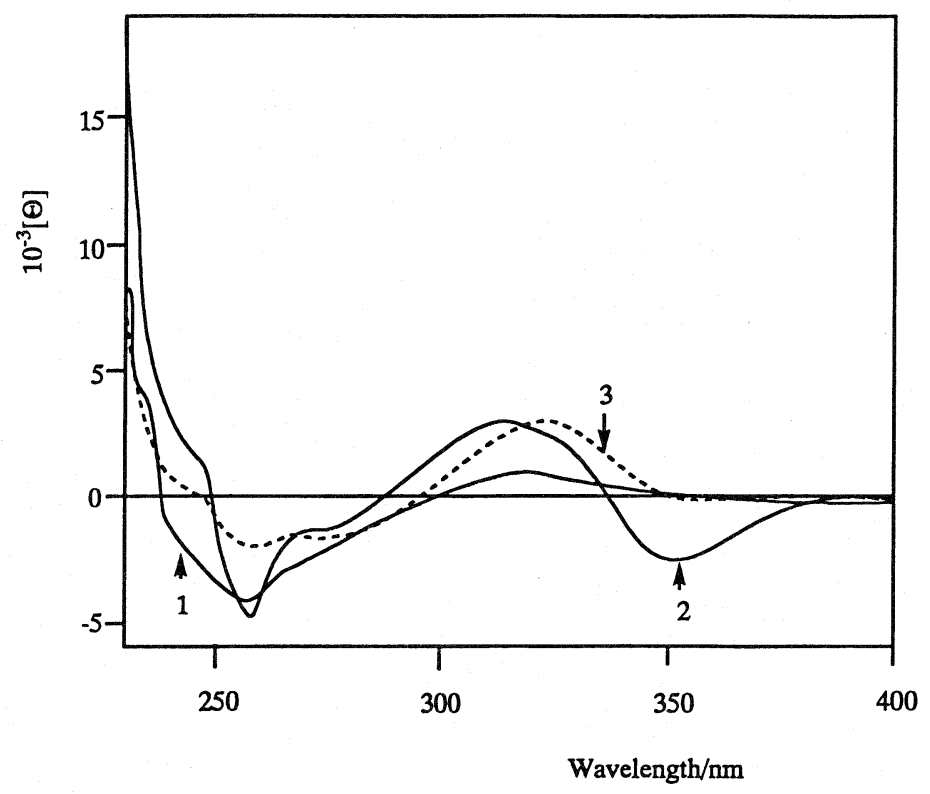

Figure 4. Induced circular dichroism spectra of $1-\beta$ in 10 vol.- $\%$ ethylene glycol aqueous solution $\left(10^{-4} \mathrm{M}\right)(1)$ and containing (-)-menthol $\left(10^{-4} \mathrm{M}\right)(2)$ and ursodeoxycholic acid $\left(10^{-4} \mathrm{M}\right)(3)$. 
host-guest complexation, hence, one way whose appended moieties are coming into the cyclodextrin cavity and another one is the moving far from the cavity with undergoing orientational changes, as illustrated in Fig. 6. The extent of a variation on the fluorescence intensity of $1-\beta$ depends on the

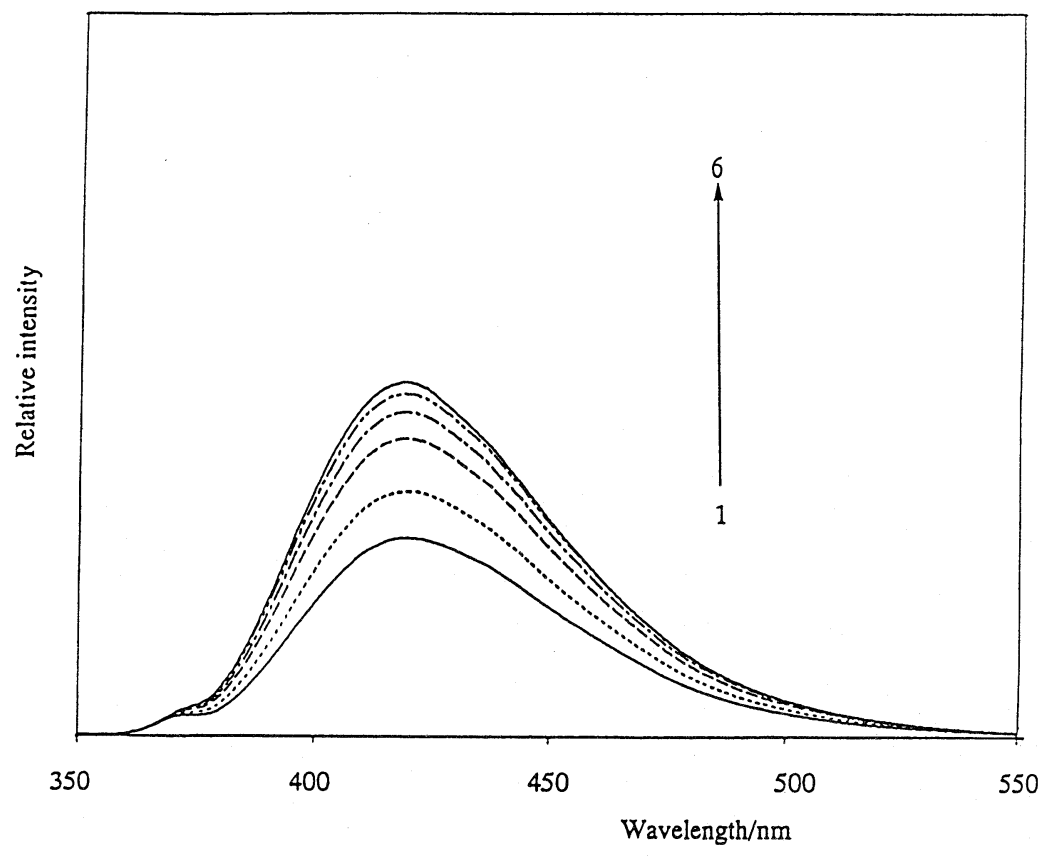

Figure 5. Fluorescence spectra of $1-\beta\left(10^{-6} \mathrm{M}\right)$ in 10 vol.- $\%$ ethylene glycol aqueous solution at various concentrations of ursodeoxycholic acid $\left(1,0 ; 2,2.0 \times 10^{-6}, 3 ; 6.0 \times 10^{-6} 4\right.$; $\left.1.2 \times 10^{-5} 5 ; 2.2 \times 10^{-5} 6 ; 4.0 \times 10^{-5} \mathrm{M}\right)$.
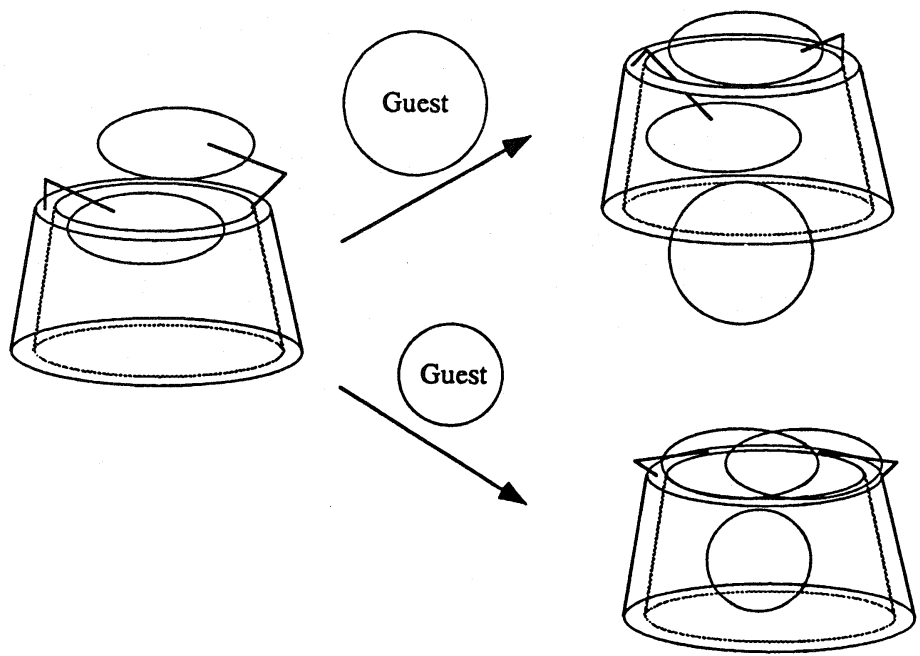

Figure 6. Host-guest complexation mechanisms of $1-\beta$ depended on the molecular size. 
nature of a guest, even at a common concentration; therefore, 1 - $\beta$ can be used to be sensing molecule as seen in the cases of sodium anthranilate modified cyclodextrin analogues reported previously. To display the sensing ability of modified cyclodextrins, the $\Delta \mathrm{I} / \mathrm{I}^{0}$ value as a sensitivity parameter was used.) Here $\Delta \mathrm{I}$ is $\mathrm{I}^{0}-\mathrm{I}$, where $\mathrm{I}^{0}$ is the fluorescence intensity for the host alone, and $\mathrm{I}$ is the fluorescence intensity for a complex. Fig. 7a shows the $\Delta \mathrm{I} / \mathrm{I}^{0}$ values of $1-\beta, 2-\beta$ and $1-\alpha$ obtained

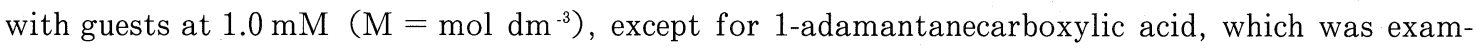
ined at $0.1 \mathrm{mM}$ because $1.0 \mathrm{mM}$ of adamantanecarboxylic acid is not soluble in pure water. The sign of $\Delta \mathrm{I} / \mathrm{I}^{0}$ values of 1 - $\beta$ for these guests except 1 -adamantanecarboxylic acid were positive, which means the fluorescence spectra decrease on guest molecular addition. On the other hand, the sign of $\Delta \mathrm{I} / \mathrm{I}^{0}$ of 2- $\beta$ and $1-\alpha$ for these guests are negative. Compound 1- $\beta$ displays almost same sensitivities for guests examined except adamantanecarboxylic acid. On the other hand, 1- $\alpha$ exhibits selectivity for (-)-menthol and 2- $\beta$ does for cyclooctanol. Steroids are biologically important substances, and it seems interesting to investigate how they are detected by these hosts. The $\Delta \mathrm{I}^{\prime} \mathrm{I}^{0}$ values of 1- $\beta, 2-\beta$ and 1- $\alpha$ obtained with steroids are shown in Fig. 7b. Because of the solubility

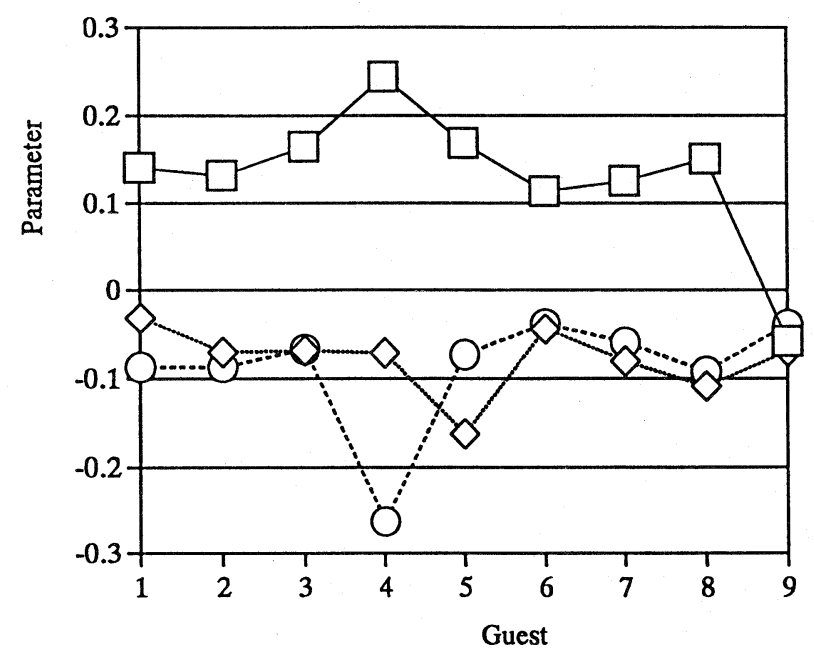

Fig.7a

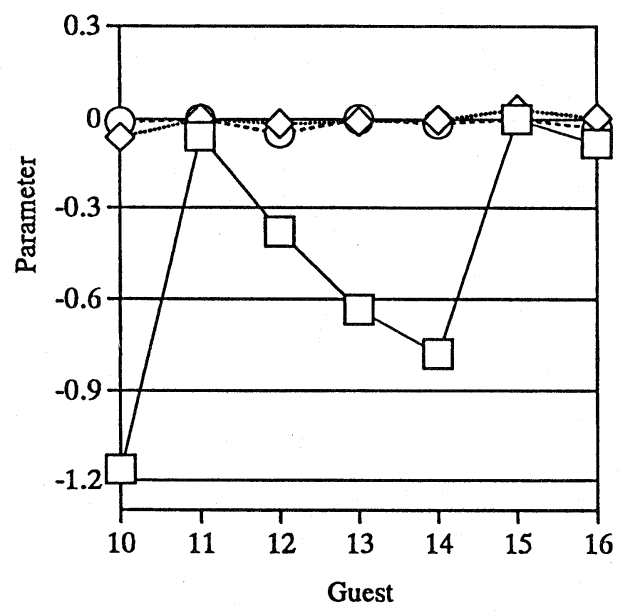

Fig. 7b

Figure 7. Sensitivity parameters of $1-\beta(-\square-), 2-\beta(\cdots \cdots \triangleright \cdots \cdots)$ and 1- $\alpha$ (----- ----$)$ for small guests $(7 \mathrm{a})$ and larger guests $(7 \mathrm{~b})$. 
of guest molecules, all steriodal guests were examined at $0.01 \mathrm{mM}$. Among these hosts, 1 - $\beta$ exhibits the highest sensitivity for the guests, of which the $\Delta \mathrm{I} / \mathrm{I}^{0}$ values for the guests except cholic acid are negative, which means the fluorescence intensity decreases upon guest addition. Compound 1- $\beta$ recognizes lithocholic acid (10) with the greatest sensitivity, exhibiting values of -1.07 for $\Delta \mathrm{I} / \mathrm{I}^{0}$. Heodeoxycholic acid (14) and ursodeoxycholic acid (13), which bear an extra hydroxyl group compared with lithocholic acid, were detected with the next highest sensitivity. Chenodeoxycholic acid (12) and ursodeoxycholic acid are different only in the configuration of the hydroxyl group at C-7 of the steroidal framework. However, the $\Delta \mathrm{I} / \mathrm{I}^{0}$ value for 12 of $1-\beta$ is one-second compared to 13 . Deoxycholic acid, which bears the same number of hydroxyl group, but in different configuration of 13 and 14, was detected with lower sensitivity. Cholic acid (15), which bears an additional hydroxyl group compared to 13 and 14, was hardly detected by $1-\beta$. These results suggest that the existence of hydroxyl group at $\mathrm{C}-12$ of the steroidal framework and the increase of guest polarity affect on the decrease of the sensitivity of 1- $\beta$ system. On the other hand, dehydroepiandrosteron (16), which bears only one hydroxyl group in the framework, was hardly detected by $1-\beta$. Although the reason for the differences observed among the steroidal compounds is not clear, the observation suggests that the structures of the complexes are affected by hydrogen bonding bctween hydroxyl groups of cyclodextrin and the steroids. Both 1- $\alpha$ and 2- $\beta$ show little sensitivities for the steroidal guest. The low sensitivity of $2-\beta$ is probably caused by the very low mobility of the cap, which is bound to $6 \mathrm{~A}$ and $6 \mathrm{D}$ glucose units of the cyclodextrin directly. It can be estimated that 2- $\beta$ probably should make a host-guest complex with a higher extent than that native $\beta$-cyclodextrin, because the appended cap can work as a hydrophobic residue to elevate binding ability. Unfortunately, here, the appended cap cannot work as a good probe of the host-guest

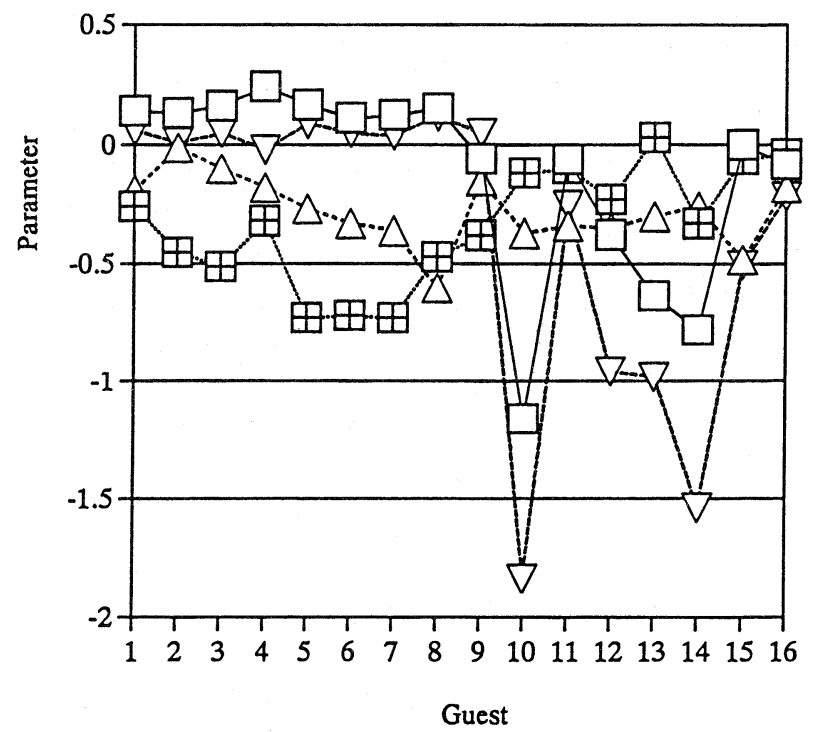

Figure 8. Sensitivity factors of $\mathbf{1}-\beta(-\square-), \mathbf{3}-\beta \quad(\cdots \cdots \boxplus \cdots \cdots), \mathbf{1}-\boldsymbol{\gamma}\left(---\triangle_{-----)}\right.$ and 2- $\gamma$ (---- $\nabla-----)$ for all guests examined. 
complexation. It is known that $\gamma$-cyclodextrin can recognize larger molecules with much sensitivity than that of $\beta$-cyclodextrin because of their cavity size. However, 1- $\beta$ exhibits higher sensitivity for bile acids than terpenoids. Fig. 8 illustrates the sensitivity factors for all guests examined of 1$\beta, 3-\beta$ and 1- $\gamma, 2-\gamma$, which are mono and bis-anthranilate modified $\beta$-and $\gamma$-cyclodextrin derivatives, respectively. It is interesting that both disubstituted cyclodextrins (1- $\beta$ and 2- $\gamma$ ) show similar sensing pattern for guests. The binding constants $(\mathrm{K})$ of $1-\beta$ for bile acids were obtained to compare the binding ability of those of $\gamma$-cyclodextrin analogues (1- $\gamma$ and $2-\gamma)$. The guestinduced fluorescence variations at $424 \mathrm{~nm}$ was used to the binding constants of 1 - $\beta$, by using Eq.1. ${ }^{6}$

$$
\frac{1}{I_{f}-I_{f 0}}=\frac{1}{a[G]_{0}}+\frac{1}{a[C D]_{0} K} \frac{1}{[G]_{0}} \quad \text { Eq.1 }
$$

Here, $I$ is the fluorescence intensity at $424 \mathrm{~nm}$ ( $I_{\mathrm{f}}$ for complex, $I_{\mathrm{f} 0}$ for the host alone), [CD $]_{0}$ is the total host concentration, $[\mathrm{G}]_{0}$ is the total guest concentration and a is constant. The binding constants of 1- $\beta, 1-\gamma$ and 2- $\gamma$ for bile acids are shown in Table 1 . Compound 1- $\beta$ shows the higher binding constants for ursodeoxycholic acid and hyodeoxycholic acid than those of $2-\gamma$.

\section{Conclusion}

Tbree types of anthranilate modified cyclodextrin analogues have been prepared to investigate their sensing ability for terpenoids and bile acids. Compound 1- $\beta$ exhibits high-sensitivity and selectivity of molecular recognition for bile acids, but hardly detects small guest such as terpenoids. The host-guest binding property of $1-\beta$ is not similar with those of $\beta$-cyclodextrin analogues (2- $\beta$ and 3- $\beta$ ), but much similar to the $\gamma$-cyclodextrin analogues (1- $\gamma$ and 2- $\gamma$ ). Compound 2- $\beta$ and 1 -

Table I. Binding constants $\left(\mathrm{K} / \mathrm{mol}^{-1} \cdot \mathrm{dm}^{3}\right)$ of $\left.1-\beta, 1-\gamma^{\mathrm{a}}\right)$, and $\left.2-\gamma^{\mathrm{a}}\right)$

\begin{tabular}{lrrr}
\hline \multicolumn{1}{c}{ Guest } & \multicolumn{1}{c}{$1-\beta$} & \multicolumn{1}{c}{$1-\gamma$} & \multicolumn{1}{c}{$2-\gamma$} \\
\hline lithocholic acid(10) & $180,000 \pm 22,000$ & $600,000 \pm 22,000$ & $1400,000 \pm 90,000$ \\
deoxycholic acid(11) & - & $79,000 \pm 4,100$ & $76,000 \pm 14,000$ \\
chenodeoxycholic acid(12) & $61,000 \pm 1,300$ & $120,000 \pm 3,000$ & $78,000 \pm 2,100$ \\
ursodeoxycholic acid(13) & $170,000 \pm 8,500$ & $270,000 \pm 9,900$ & $95,000 \pm 2,200$ \\
hyodeoxycholic acid(14) & $350,000 \pm 9,800$ & $610,000 \pm 33,000$ & $190,000 \pm 5,200$ \\
cholic acid(15) & - & $13,000 \pm 1,300$ & $15,000 \pm 1,500$ \\
dehydroepiandrosterone(16) & - & $120,000 \pm 9,600$ & $26,000 \pm 610$ \\
& & & \\
\hline
\end{tabular}

a) Reported in Ref. 4-c. 
$\alpha$ show small sensitivity for guests, because of the small cavity size of $\alpha$-cyclodcxtrin and the restricted flexibility of the appended moiety, respectively. It is obvious that the fluorescent-sensory system using such modified cyclodextrins is very convenient and useful method, because the chemical modification of a guest molecular, which is even spectroscopic inert is not necessary; a guest can be examined directly in this system.

\section{References}

1. F. Vogtle, "Supramolecular Chemistry", John Wiley \& Sons, Chichester (1991)

2. a) I. Tabushi, K. Shimokawa, H. Shirakata, and K. Fujia, J. Am. Chem. Soc., 98, 7855 (1976);

b) R. Breslow, J. Doherty, G. Guillot, and C. Lipsey, ibid, 100, 3227 (1978) ; c) R. Bresslow, P. Bovy, and C. Lipsey, ibid, 102, 2115 (1980); d) R. Breslow and A. W.Czarnik, ibid, 105, 1390 (1983) ; e) I. Tabushi, Y. Kuroda, H. Higashimura, and R. Breslow, ibid, 107 , 5545 (1985) ; f) E. U. Akkaya and A. W. Czarnik, ibid, 110, 8553 (1988).

3. a) F. Moriwaki, H. Kaneko, A. Ueno, T. Osa, F. Hamada, and K. Murai, Bull. Chem. Soc.Jpn., 60, 3619 (1987) ; b) A. Ueno, F. Moriwaki, T. Osa, F. Hamada, and K. Murai , J. Am. Chem. Soc., 110, 4323 (1988) ; c) A. Ueno, F. Moriwaki, T. Matsue, T. Osa, F. Hamada, and K. Murai, Makromol. Chem., Rapid Commun., 6, 231 (1985) ; d) F. Hamada, M. Fukushima, T. Osa, and A. Ueno, ibid, 14, 279 (1993) ; e) F. Hamada, R. Ito, I. Suzuki, T. Osa, and A. Ueno, ibid, 15, 531 (1994);

4. a) F. Hamada, Y. Kondo, K. Ishikawa, H. Ito, I. Suzuki, T. Osa, and A. Ueno, J. Incl. Phenom., 17, 267 (1994) ; b) F. Hamada, K. Ishikawa, R. Ito, S. Hamai, I. Suzuki, T. Osa, and A. Ueno, ibid, 20, 43 (1995) ; c) F. Hamada, K. Ishikawa, I. Tamura, and A. Ueno, Anal. Sci., 11, 935 (1995).

5. F. Moriwaki, H. Kaneko, A. Ueno, T. Osa, F. Hamada, and K. Murai, Bull. Chem. Soc. Jpn., 60, 3619 (1987).

6. S. Hamai, Bull. Chem. Soc. Jpn., 55, 2721 (1982). 